
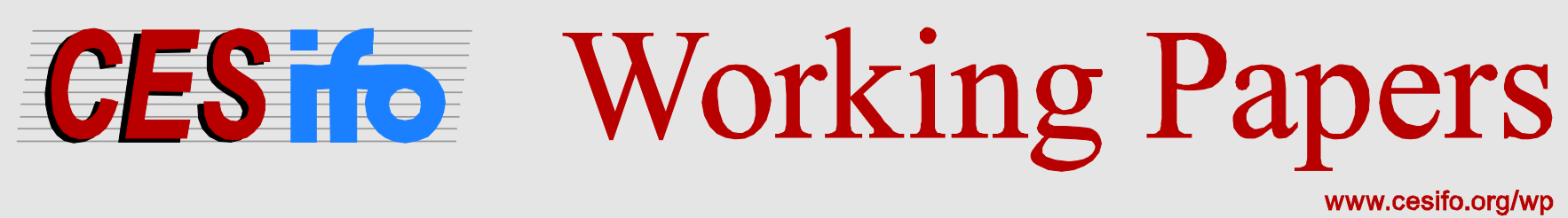

\title{
Supply Side Climate Policy and the Green Paradox
}

\author{
Michael Hoel
}

\section{CESIFO WORKING PAPER NO. 4094 \\ CATEGORY 10: ENERGY AND CliMATE ECONOMICS \\ JANUARY 2013}

Presented at CESifo Area Conference on Energy \& Climate Economics, November 2012

An electronic version of the paper may be downloaded

- from the SSRN website:

- from the RePEc website:

- from the CESifo website:

WWW.SSRN.com

www.RePEc.org

www.CESifo-group.org/wp

\section{CESifo}




\title{
Supply Side Climate Policy and the Green Paradox
}

\begin{abstract}
The focus of the green paradox literature has been either on demand-side climate policies or on effects of technological changes. The present paper addresses the question of whether there also might be some kind of green paradox related to supply-side policies, i.e. policies that permanently remove some of the carbon resources. The conclusion is that there will no green paradox if supply-side climate policies are aimed at high-cost carbon reserves. If instead lowcost reserves are removed, the possibility that both early and total emissions increase cannot be ruled out. Hence, "wrong" supply-side climate policies may give a supply-side green paradox.
\end{abstract}

JEL-Code: Q300, Q380, Q540, Q580.

Keywords: climate, green paradox.

\author{
Michael Hoel \\ Department of Economics \\ University of Oslo \\ P.O. Box 1095, Blindern \\ Norway-0317 Oslo \\ m.o.hoel@econ.uio.no
}

January 14, 2013

I am grateful to participants at seminars in Oslo, Venice and Munich for useful comments. While carrying out this research I have been associated with CREE - Oslo Center for Research on Environmentally friendly Energy. CREE is supported by the Research Council of Norway. 


\section{Introduction}

Unless all countries cooperate on demand-side climate policies such as a carbon tax, it is well-known that the attempts of some countries to reduce carbon emission demand-side climate policies, such as a carbon tax or emission quotas, may be undermined by increased emission by other countries, so called carbon leakage. An early discussion of this was given by Bohm (1993), who also discussed alternative policies that to a less extent were vulnerable to carbon leakage. One of the policies discussed by Bohm was supply-side policies, i.e. policies aimed at reducing the supply of fossil fuels instead of the use of fossil fuels. This idea was followed up by Hoel (1994), where a cooperating group of countries had to take into account the response of a group of non-cooperating countries. It was shown that the optimal policy tax policy for the group of cooperating countries was a combination of a tax on their production of fossil fuels and a tax on their use of fossil fuels. The sum of the tax rates was shown to be equal to the Pigovian rate, while the mix between the two tax rates depends on the demand and supply elasticities. More recently, Harstad (2012) has shown that a first-best outcome may be achieved if a group of cooperating countries can buy the reserves with the highest costs and keep them permanently out of production.

None of the literature above focuses explicitly on the fact that fossil fuels are non-renewable resources. An early contribution having this focus was given by Sinclair (1992). Sinclair pointed out that "the key decision of those lucky enough to own oil-wells is not so much how much to produce as when to extract it." Since then, there has been a considerable number of contributions discussing optimal climate policy with explicit attention given to the nonrenewable character of carbon resources. These contributions either assume a constraint on the amount of carbon in the atmosphere (Chakravorty et al. 2006, 2008, 2012) or explicitly include a climate cost function in the analysis (Ulph and Ulph, 1994; Withagen, 1994; Tahvonen, 1995; Farzin and Tahvonen, 1996; Hoel and Kverndokk, 1996). One of the insights from the literature is that the principles for setting an optimal carbon tax (or price of carbon quotas) are the same as when the limited availability of carbon 
resources is ignored: At any time, the optimal price of carbon emissions should be equal to the present value of all future climate costs caused by present emissions, often called the social cost of carbon.

During the last half decade, there has been a renewed interest in analyzing climate policy with explicit attention given to the non-renewable character of carbon resources. Much of this later literature discusses the so-called "green paradox", a term stemming from Sinn (2008a,b). Sinn argues that some designs of climate policy, intended to mitigate carbon emissions, might actually increase carbon emissions, at least in the short run. Sinn's point is that if e.g. a carbon tax rises sufficiently rapidly, profit maximizing resource owners will bring forward the extraction of their resources. Hence, in the absence of carbon capture and storage (CCS), carbon emissions increase. ${ }^{1} \mathrm{~A}$ thorough analysis of the effects of taxation on resource extraction was given by Long and Sinn (1985), but without explicitly discussing climate effects. More recently, Hoel $(2011,2012)$ has studied the relationship between carbon taxes and carbon extraction emphasizing the fact that governments in practise cannot commit to future tax rates.

A rapidly increasing carbon tax is not the only possible cause of a green paradox. A declining price of a substitute, either because of increasing subsidies or technological improvement, can give the same effect: see e.g. Strand (2007), Gerlagh (2011), Grafton et al. (2010), and van der Ploeg and Withagen (2010).

As mentioned above, Sinn used the term "green paradox" to describe a situation where policies intending to mitigate climate change actually increase near-term emissions. Gerlagh (2011) uses the term "weak green paradox" for such a phenomenon, and uses the term "strong green paradox" to describe a situation where policies intending to mitigate climate change increase total climate costs. This distinction is important, since total climate costs depend not only on near-term emissions, but also on all future emissions. One can therefore imagine policies that increase near-term emissions, but that never-

\footnotetext{
${ }^{1}$ Throuout this paper CCS is ignored; see e.g. Hoel and Jensen (2012) for a discussion of climate policy when there is a possibility of CCS and when the carbon resource scarcity is explicitly taken into considereation.
} 
theless reduce future emissions so much that total climate costs decline.

While the focus of the green paradox literature described above has been either on demand-side climate policies or on effects of technological changes, the present paper addresses the question of whether there also might be some kind of green paradox related to supply-side policies. To be more precise: Can a permanent removal of some fossil fuel resources increase early emissions, and perhaps even increase total climate costs? This issue is discussed in section 4 and 5, after first presenting the model and discussing demand-side policies in the form of a carbon tax in sections 2 and 3. The short conclusion is that there will no green paradox if supply-side climate policies are aimed at high-cost carbon reserves. If instead low-cost reserves are removed, the possibility that both early and total emissions increase cannot be ruled out. Hence, "wrong" supply-side climate policies may give a supply-side green paradox.

\section{Extraction costs and the equilibrium ex- traction path}

In the simplest Hotelling type models of resource extraction it is assumed that unit extraction costs are constant (often normalized to zero), and that the available amount of the resource is given exogenously. A more interesting and more realistic case is when the unit cost of extraction is increasing in accumulated extraction, denoted $c(A)$, where $A$ is accumulated extraction. This is a specification frequently used in the resource literature, see e.g. Heal (1976) and Hanson (1989). Notice that the first case mentioned is a special case of this more general description. Constant extraction costs and a fixed amount of resources implies that the cost function $c(A)$ has an inverse $\mathrm{L}$ shape, with the vertical part of the function being at the level $A^{*}$ corresponding to the exogenously fixed amount of the resource.

The resource considered may either be interpreted as an aggregate of all fossil fuel resources, or it may be interpreted more narrowly as oil. For most of the present analysis it makes no difference what interpretation is used, but 
the issue will be discussed further in section 6 . The resource is henceforth simply called carbon.

Extraction of the carbon resource at time $t$ is denoted $x(t)$ and the consumer price is $p(t)$. The demand function is $D(p)$ and is assumed constant over time. It is also assumed that demand is zero if the price is sufficiently high. Formally, there is a choke price $\bar{p}$ such that $D(p)=0$ for $p \geq \bar{p}$, and $D(p)>0$ and $D^{\prime}(p)<0$ for $p<\bar{p} .^{2}$ There may also be a perfect substitute for the carbon resource that has a unit cost of extraction equal to $b<\bar{p}$ and that is available at a flow rate of at least $D(b)$ and without any limit on cumulative production. Although the existence of such a backstop technology for most of the analysis is of little importance, it will be assumed henceforth, as this makes some of the discussion slightly simpler.

Producers are price takers and face an exogenous interest rate $r$. Producers choose the extraction path $x(t)$ to solve the following optimization problem:

$$
\begin{gathered}
\max \int_{0}^{\infty} e^{-r t}\{p(t)-c(A(t))\} x(t) d t \\
\text { s.t. } \dot{A}(t)=x(t)
\end{gathered}
$$

Together with the condition that extraction at any time must be equal to demand this gives the following equilibrium condition (see the Appendix for a formal analysis):

$$
\begin{aligned}
\dot{p}(t) & =r[p(t)-c(A(t))] \\
x(t) & =D(p(t)) \\
p\left(t^{*}\right) & =b \\
c\left(A\left(t^{*}\right)\right) & =b
\end{aligned}
$$

where $t^{*}$ is the date at which a switch from carbon extraction to backstop

\footnotetext{
${ }^{2}$ This is a purely technical assumption. If it instead had been assumed that $D(p)>0$ for all $p$ but approached zero as $p \rightarrow \infty$, it would nevertheless be true that for some high price $\bar{p}$ (e.g. a million dollars per barrel of oil) demand would be so small that it would be of no practical interest (e.g. 1 barrel of oil per year).
} 
production occurs. ${ }^{3}$

The equilibrium is illustrated in Figure 1, where the curve for $c(A)$ and the equilibrium price path $p=\pi(A)$ for simplicity are drawn linearly, although this will of course generally not be the case.

$* * *$

Insert Figure 1

$* * *$

The steepness of the equilibrium price path $\pi(A)$ is given by ${ }^{4}$

$$
\pi^{\prime}(A)=r \frac{p-c(A)}{D(p)}
$$

implying that the path is steeper the larger is $p$ and the lower is $A$. For any initial price $p(0)$, the development of $\pi(A)$ follows from (2) and (3). The equilibrium value of $p(0)$ is determined so that $p(t)$ and $c(A(t))$ reach $b$ simultaneously. Had we started with a $p(0)$-value lower than the one drawn in Figure 1, the curve $\pi(A)$ would be less steep than the one drawn, and would therefore cross the curve for $c(A)$ at a value of $p$ below $b$ and then start to decline, which violates our equilibrium conditions. Similarly, starting with a $p(0)$-value above the one drawn in Figure 1, the curve $\pi(A)$ would be steeper than the one drawn, and would hence reach $b$ at a value of $A$ giving $c(A)<b$, which also violates our equilibrium conditions.

Consider a positive shift in the extraction cost function, i.e. a change in the cost function from $c(A)$ to $c(A)+\varepsilon(A)$ where $\varepsilon(A) \geq 0$ for all $A$ with a strict inequality holding for some range of $A$ between 0 and $A^{*}$ defined by $c\left(A^{*}\right)=b$. It follows from (7) that such a shift in the cost function must shift the whole equilibrium price path $\pi(A)$ upwards. The reason for this is that a hypothetical price path that is anywhere equal to or below the original $\pi(A)$ will be less steep than the original path for the $A$-values having $\varepsilon(A)>0$.

\footnotetext{
${ }^{3}$ If there were no backstop with $b<\bar{p}$ the conditions $p(t)=\bar{p}$ and $c(A)=\bar{p}$ would only be reached asymptotically.

${ }^{4}$ This follows from $\pi(A)=p(t(A))$ where $t(A)$ is the inverse of $A(t)$. Using (2) and (3) for $A^{\prime}(t)$ and $p^{\prime}(t)$ gives $(7)$.
} 
This hypothetical price path would hence not reach $b$, and thus cannot be an equilibrium path.

This important result may be formulated as a Proposition:

Proposition $1 A$ positive shift of the cost function $c(A)$ for any $A<A^{*}$, where $A^{*}$ is defined by $c\left(A^{*}\right)=b$, will shift the whole price path $p=\pi(A)$ upwards, and hence delay extraction.

Two examples of shifts are given in Figures 2 and 3. In Figure 2 the cost shift occurs only for low values of $A$, implying that $A^{*}$ is unaffected by the cost shift. The whole price path shifts upwards as illustrated in Figure 1a. The time path for $A(t)$ is illustrated in Figure 2b. Both before and after the shift the curve for $A(t)$ becomes flatter over time, since $\dot{A}(t)=D(p(t))$ declines as $p(t)$ increases. Since the new price path has a higher value of $p$ for any given value of $A$ after the cost increase than before, the aftershift (dotted) curve in the $(t, A)$ space is flatter (lower $\dot{A}(t)=D(p(t))$ ) for any given $A$ than the before-shift (fully drawn) curve. At any date prior to the switch from the resource to the backstop cumulative extraction is hence lowered as a consequence of the increase in extraction costs.

$* * *$

Insert Figure 2a and $2 \mathrm{~b}$ beside each other $* * *$

In Figure 3 the cost shift occurs only for high values of $A$, implying that total extraction is reduced to $A^{* *}$ as a consequence of the cost shift. As in the previous case, the whole price path shifts upwards as illustrated in Figure 2a. As in the previous case, the curve for $A(t)$ becomes flatter over time, see Figure $3 \mathrm{~b}$. At any date prior to the switch from the resource to the backstop cumulative extraction is hence also in this case lowered as a consequence of the increase in extraction costs.

***

Insert Figure $3 \mathrm{a}$ and $3 \mathrm{~b}$ beside each other $* * *$ 


\section{The effects of a carbon tax}

As mentioned in the Introduction, the effects of a carbon tax when carbon emissions are explicitly modeled as coming from the use of a scarce carbon resource has been extensively studied in the literature. Some consequences of a carbon tax follow immediately from Proposition 1: A constant carbon tax (per unit of carbon emissions) of size $\theta$ simply means that the unit cost function will be changed from $c(A)$ to $c(A)+\theta$. From Proposition 1 it follows that the whole equilibrium price path will be shifted upward. Moreover, total extraction will be reduced from $A^{*} \equiv A^{*}(0)$ to $A^{*}(\theta)$, where $A^{*}(\theta)$ is defined by $c\left(A^{*}(\theta)\right)+\theta=b$.

According to Allen et al. (2009), the peak temperature increase due to greenhouse gas emissions is approximately independent of the timing of emissions. In the framework of the present model, peak temperature increase thus depends only on $A^{*}(\theta)$. However, we would expect this peak temperature increase to occur earlier the more of the emissions occur at an early stage. It also seems reasonable to expect climate costs to be higher the more rapidly the temperature increases, for a given peak temperature increase. Hence, it seems reasonable to assume that climate costs are increasing not only in $A^{*}(\theta)$, but also in the speed of extraction.

For an inverse $\mathrm{L}$ cost function (i.e. $c(A)$ constant for $A>A^{*}$ and becoming vertical at $A^{*}$ ), total extraction is independent of a carbon tax (unless it is so high that the resource rent is driven to zero, see Hoel (2012)). A main point in the green paradox literature, and emphasized by Sinn (2008a,b), is that if the carbon tax is expected to rise sufficiently rapidly, this may speed up resource extraction, and hence be bad for the climate. Formally (and independent of the cost function) a carbon tax implies that the producers' optimization problem (1) gets an additional term $-T$ where $T$ is the present value of carbon taxes paid:

$$
T=\int_{0}^{\infty} e^{-r t} \theta(t) x(t) d t
$$


If the present value of the tax rate is constant this may be rewritten as

$$
T=\theta(0) A^{*}
$$

In the inverse $\mathrm{L}$ case $A^{*}$ is exogenous, implying that producers cannot influence $T$. A carbon tax rate that is rising at the rate of interest hence has no effect on the extraction path in this case. However, if the present value of the carbon tax rate is rising over time, producers can reduce $T$ be speeding up extraction. In this case the tax is hence detrimental to the climate compared with the case of no tax. ${ }^{5}$

For the general case a positive carbon tax, whatever way it evolves over time, will reduce total extraction. Consider first a carbon tax for which the present value of the tax rate is constant. For this case producers can only affect $T$ by the choice of how much to totally extract. Let the level of the tax rate be such that the optimal response to the carbon tax is to reduce $A$ from $A^{*}$ to $A^{* *}$. The effect of the carbon tax on the extraction path is therefore identical to imposing an exogenous upper limit $A^{* *}$ but having no carbon tax. From Proposition 1 it follows that the carbon tax will shift the whole equilibrium price path $\pi(A)$ upwards. Hence, a carbon tax rate increasing at the rate of interest will reduce both total extraction and postpone extraction in a similar matter as in Figure 2b. Such a tax is unambiguously good for the climate; there is no green paradox.

Finally, consider a carbon tax that is rising more rapidly than the rate of interest. Also in this case total extraction will decline, say to $A^{* *}$. However, in this case producers have an incentive to speed up extraction compared with a case with no tax and an exogenous upper limit $A^{* *}$ on cumulative extraction. If the carbon tax is rising fast enough, this negative effect on $p(0)$ may be stronger than the positive effect on $p(0)$ from total extraction being reduced. In the terminology of Gerlagh (2011), there will in this case be a "weak green paradox", meaning that initial extraction increases as a response to the carbon tax. A "strong green paradox" (Gerlagh, 2011),

\footnotetext{
${ }^{5}$ Since governments in practice cannot commit to the size of the carbon tax rate for more than a few years, the comparizon with "zero tax forever" might not be particularly relevant, see Hoel (2012) for a further discussion.
} 
meaning that the total discounted climate costs increase, cannot be ruled out, but is less likely the stronger is the effect on total extraction compared with the effect on initial extraction (see Hoel, 2011) for a further discussion of these issues).

\section{Supply-side climate policies}

For the reasons given in the Introduction, the rest of this paper studies the effects of supply-side climate policies. By supply-side policies we mean policies that permanently remove some of the carbon resources. To focus on these policies, carbon taxes and other demand-side policies are ignored.

Removing some of the carbon resources is equivalent to a leftward shift the cost function $c(S)$. The simplest case is the inverse $\mathrm{L}$ case. Removing some of the resources simply means shifting the vertical part $A^{*}$ leftward. Such a reduction in the available resource supply shifts the whole price path upward. Hence both total and initial resource extraction is reduced, which is unambiguously beneficial to the climate.

Also for the more general case removing some of the resources implies a leftward shift in the cost function. This is illustrated in Figure 4a for the case of a reduction in the resources with the lowest costs in the amount $A^{* *}-A^{*}$, and in Figure 5a for a reduction in the resources with the highest costs, also here in the amount $A^{* *}-A^{*}$.

$* * *$

Insert Figure $4 \mathrm{a}$ and $4 \mathrm{~b}$ beside each other $* * *$

It follows from Proposition 1 that whichever types of resources are removed, the equilibrium price path $\pi(A)$ must increase. Moreover, total extraction must decline. The climate effect of such a supply-side policy is hence unambiguously good.

$* * *$

Insert Figure 5a and 5b beside each other 


\section{Emissions from the extraction process}

While most of the emissions from fossil fuels come from the end-use of the fuels, there are also considerable emissions from the extraction process. Resource extraction requires energy, and a large part of this energy typically comes from the use of fossil fuels. This is the reason why some types of unconventional fuel (e.g. oil sand) often is assumed to be particularly bad for the climate. The emissions from the final oil product, e.g. gasoline or diesel for transportation, has the same amount of carbon emissions as other fuel has. However, the process of extracting and refining oil sands gives much higher carbon emissions than the process of extracting and refining conventional oil.

Emissions from the extraction and refining process are modeled as follows. Non-energy extraction costs are given by $\tilde{c}(A)$ where $c(A)$ is increasing in $A$. These costs represent the use of all inputs except the inputs of fossil fuels. In addition to these inputs we need the input of $\gamma(A)$ units of fossil fuels to extract 1 unit of fossil fuels, and it is assumed that $\gamma^{\prime}(A)>0$. In other words, as we move from lower-cost to higher-cost resources, both non-energy and energy costs are assumed to rise. ${ }^{6}$

Notice that if there exists a value $\bar{A}$ defined by $\gamma(\bar{A})=1$ this will be an upper limit to what the endogenously determined total extraction $A^{*}$ can be, since extracting beyond $\bar{A}$ would require more energy than produced.

With this modification of the cost assumptions, the producers' optimization problem is changed to

$$
\max \int_{0}^{\infty} e^{-r t}\{p(t)[1-\gamma(A)]-\tilde{c}(A)\} x(t) d t
$$

\footnotetext{
${ }^{6}$ The terms non-energy costs and energy costs should more accurately be called nonfossil fuel costs and fossil fuel costs. If some of the energy is covered by non-carbon energy, this should be included in $\tilde{c}(A)$. Notice that it is implicitly assumed that the ratio between the use of carbon energy and other inputs is independent of the price of carbon energy. This assumption of a zero elesticity of substitution is clearly a simplification, but is not important for the results of the analysis.
} 
subject to (2).

This optimization problem is solved in the Appendix. Defining the function $c(A)$ by

$$
c(A)=\frac{\tilde{c}(A)}{1-\gamma(A)}
$$

the equilibrium conditions (3), (5) and (6) remain valid, while (4) is changed to

$$
x(t)=\frac{D(p(t))}{1-\gamma(A(t))}
$$

As before, the equilibrium price will be increasing over time. Regarding emissions, however, it is no longer obvious that they will decline over time. As before, the rising carbon price implies that emissions from final use will be declining over time. However, since $\gamma(A(t))$ is increasing over time, this implies that emissions in the extraction process per unit of final use will be increasing. Formally, the ambiguity in the time path of $x(t)$ follows from (9), since $D(p(t))$ will be declining while $\gamma(A(t))$ will be increasing. To focus on the latter aspect, it is assumed in the rest of this section that demand is completely inelastic. $^{7}$

When demand $D$ is constant, it follows from (9) that emissions will be increasing until the resource price reaches $b$ at the date $t^{*}$ when the switch from resource extraction to backstop production occurs. This is illustrated by the fully drawn curves in Figures $4 \mathrm{~b}$ and $5 \mathrm{~b}$.

To understand the effects of removing some of the resource supply it is useful to consider the two extremes of removing the lowest-cost resources and removing the highest-cost resources, as illustrated in Figures $4 \mathrm{a}$ and $5 \mathrm{a}$, respectively. In both cases total extraction is reduced from $A^{*}$ to $A^{* *}$. When the highest-cost resources are removed, the new emission path will be identical to the old one except that emissions will drop to zero, at $t^{* *}$ instead of $t^{*}$ in Figure 4b. The total emission reduction is denoted $\mathrm{R}$ in this Figure, and is unambiguously beneficial for the climate.

When the lowest-cost resources are removed the cost function will be shifted leftward as illustrated in Figure 5a. A similar shift will occur for $\gamma(A)$.

\footnotetext{
${ }^{7}$ This of cource means that there must exist a backstop with unit cost $b$.
} 
This means that the initial emission path will shift upward as illustrated in Figure 5b until the new (and lower) switch date $t^{* *}$. Emissions will hence increase by an amount I prior to $t^{* *}$ in Figure $5 \mathrm{~b}$, but will decline by an amount $\mathrm{R}$ after $t^{* *}$. $\mathrm{R}$ is larger than $\mathrm{I}$, since total extraction is reduced from $A^{*}$ to $A^{* *}$. But to the extent that early emissions are considered worse for the climate than later emissions, it is not obvious that this type of carbon supply reduction is good from a climate perspective.

To summarize: Removing the highest-cost resources has an unambiguously good effect on the climate. On the other hand, the effect on the climate of removing lower-cost resources is ambiguous from a theoretical point of view.

\section{A dirty backstop}

So far, the backstop has been assumed clean (in the sense that there are no carbon emissions associated with production of the backstop). This is a perhaps a natural assumption if the carbon resource is interpreted as all fossil fuels. However, if the carbon resource in the preceding analysis is interpreted more narrowly as oil of various types the assumption of a clean backstop is not obvious. The backstop to oil could e.g. be biofuel. Although biofuels sometimes are considered "climate neutral", there is a considerable literature arguing that the production of biofuel will have adverse climate effects. ${ }^{8}$ Alternatively, one could think of synthetic oil made from coal as a backstop to oil. In this case the backstop is clearly not clean in the sense described above. ${ }^{9}$

To see the consequences of the dirty backstop for oil, assume that synthetic coal a backstop technology for oil. Assume coal is availably in an unlimited amount at a cost $\tilde{b}$ per unit of carbon, and that each unit of coal

\footnotetext{
${ }^{8}$ Adverse climate effects may be caused by fossil fuel use for harvesting, transportation and production, by $\mathrm{N}_{2} \mathrm{O}$ emissions from fertilizer use and the crop itself (Crutzen et al., 2008), and by direct and indirect land-use changes (Fargione et al., 2008; Searchinger et al., 2008)

${ }^{9}$ See van der Ploeg and Withagen (2012) for a discussion of optimal carbon taxes for this case.
} 
extracted requires $\lambda^{b}$ for extraction and transformation to synthetic oil. In this case the cost of synthetic oil per unit end use is $b=\tilde{b} /\left(1-\lambda^{b}\right)$. The switch from regular oil to synthetic oil from coal will occur when accumulated oil extraction has reached $A^{*}$, where $c\left(A^{*}\right)=b$, i.e. $\tilde{c}\left(A^{*}\right) /\left(1-\lambda\left(A^{*}\right)\right)=\tilde{b} /\left(1-\lambda^{b}\right)$. If $\lambda^{b}>\lambda\left(A^{*}\right)$ emissions will increase as we switch from regular to synthetic oil. Any removal of the supply of regular oil will in this case advance the date of this transition to increased carbon emissions. Hence, in this case any removal of the supply of regular oil will be bad for the climate.

On the other hand, if $\lambda^{b}<\lambda\left(A^{*}\right)$ emissions will decline as we switch from regular to synthetic fuel. If we in this case remove high-cost reserves, the time point of the switch from regular to synthetic oil will be moved forward from $t^{*}$ to $t^{* *}$, and total emissions will unambiguously decline as illustrated by the area $\mathrm{R}$ in Figure 6a.

Insert Figure $6 \mathrm{a}$ and $6 \mathrm{~b}$ beside each other $* * *$

The situation is not so clear if low-cost oil reserves are removed. This case is illustrated in Figure 6b: As in the case of a clean backstop, we initially get an increase in emissions ( $\mathrm{I}$ in Figure $6 \mathrm{~b}$ ) but later a reduction ( $\mathrm{R}$ in Figure $6 \mathrm{~b})$. With a clean backstop $\mathrm{R}$ was higher than $\mathrm{I}$, so that total emissions declined. This is, however, not obvious when the backstop is dirty (although it is "less dirty" that the high-cost regular oil). When the backstop is dirty, we may get higher total emissions as a consequence of removing low-cost reserves, and early emissions will certainly increase (at least as long as the price effect on demand is sufficiently low). Removing low-cost oil reserves may therefore be bad for the climate when the backstop is dirty.

If the backstop for regular oil is biofuels instead of coal, the analysis is much the same. If the sum of all greenhouse gas emissions from biofuel production are sufficiently large, emissions will increase as we switch from oil to biofuel. It is probably more realistic that emissions from biofuel production are lower than the total emissions from high-cost oil reserves. If so, this gives us the cases illustrated by Figures $6 \mathrm{a}$ and $6 \mathrm{~b}$. 


\section{Conclusions}

Ignoring emissions from the extraction of fossil fuels and assuming a clean backstop, removing some of the fossil fuel reserves is unambiguously good for the climate. This conclusion is no longer obvious if emissions from extracting the fossil fuels are higher for high-cost reserves than for low-cost reserves. In this case removing low-cost reserves may increase early emissions, although total emissions go down. Removing high-cost reserves is unambiguously good for the climate also in this case, since both total and early emissions decline (including the price effect on early emissions).

If the backstop is dirty in the sense that there are greenhouse gas emissions related to the production of the backstop, the climate may be adversely affected even if high-cost reserves of carbon are removed. However, this can only occur if the emissions from the backstop are higher than from the highcost reserves of carbon resources. If the emissions from the backstop are lower than from the high-cost reserves of carbon resources, total and early emissions go down when high-cost reserves are removed. On the other hand, if low-cost reserves are removed, the possibility that both early and total emissions increase cannot be ruled out.

So the short conclusion is much in line with that of Harstad (2012): If supply-side climate policies are to be used, these policies should be aimed at the high-cost carbon reserves.

\section{Appendix: Derivation of the equilibrium}

As there are no externalities other than the climate externality, deriving the competitive equilibrium is equivalent to deriving the social optimum. Let the increasing and concave function $U(x)$ be the benefit of using the resource, with $U^{\prime}(x)=p(x)=D^{-1}(x)$ and $U^{\prime}(0)=b$. The equilibrium described by (3)-(6) in section 2 is a special case (with $\gamma=0$ ) of the equilibrium described in section 5. Ignoring the climate externality, the optimization of a social 
planner for the problem described in section 5 is

$$
\max \int_{0}^{\infty} e^{-r t}\{U([1-\gamma(A(t))] x(t))-\tilde{c}(A) x(t)\} d t
$$

subject to

$$
\dot{A}(t)=x(t) ; A(0)=0 ; x(t) \geq 0 \text { for all } t
$$

By defining $c(A)=\frac{\tilde{c}(A)}{1-\gamma(A)}$ and $y=[1-\gamma(A(t))] x$ this problem may be redefined as

$$
\max \int_{0}^{\infty} e^{-r t}\{U(y(t))-c(A(t)) y(t)\} d t
$$

subject to

$$
\dot{A}(t)=\frac{y(t)}{1-\gamma(A(t))} ; A(0)=0 ; y(t) \geq 0 \text { for all } t
$$

The current value Hamiltonian, written so the shadow price $\lambda$ is nonnegative, is

$$
H(y, A, \lambda)=U(y)-c(A) x-\lambda \frac{y}{1-\gamma(A)}
$$

and the optimum conditions are (omitting time references where this cannot cause many misunderstanding)

$$
\begin{gathered}
\frac{\partial H}{\partial y}=U^{\prime}-c(A)-\frac{\lambda(t)}{1-\gamma(A)} \leq 0 \text { with }=\text { for } y(t)>0 \\
\dot{\lambda}(t)=r \lambda(t)-\frac{\partial H}{\partial A}
\end{gathered}
$$

giving

$$
\dot{\lambda}=r \lambda-y c^{\prime}-\frac{\lambda y \gamma^{\prime}}{(1-\gamma)^{2}}
$$

The tranversality condition for this problem is

$$
\operatorname{Lim}_{t \rightarrow \infty} e^{-r t} \lambda(t) A(t)=0
$$


Whenever extraction is positive it follows from (11) and $U^{\prime}=p$ that

$$
p(t)=c(A)+\frac{\lambda(t)}{1-\gamma(A)}
$$

Using (10) it follows that

$$
\dot{p}(t)=c^{\prime}(A) \frac{y}{1-\gamma}+\frac{\dot{\lambda}(t)}{1-\gamma}+\frac{\lambda y \gamma^{\prime}}{(1-\gamma)^{3}}
$$

Inserting (15) and (13) into this expression gives us the equilibrium condition for the price path:

$$
\dot{p}(t)=r[p(t)-c(A(t))]
$$

From (11) it is clear that if extraction stops while $\lambda \neq 0$, the trasversality condition will be violated. Similarly, if $\lambda$ becomes negative, it follows from (11) that the transversality condition will be violated. The equilibrium time path of $\lambda(t)$ therefore must reach zero when extraction stops. In other words, $p\left(t^{*}\right)=c\left(A\left(t^{*}\right)\right)$ at the date $t^{*}$ when extraction stops, and at this date we must have $U^{\prime}(0)=p\left(t^{*}\right)$, i.e. $p\left(t^{*}\right)=b$.

\section{References}

Allen, M. R., D. J. Frame, C. Huntingford, C. D. Jones, J. A. Lowe, M. Meinshausen and N. Meinshausen (2009). Warming caused by cumulative carbon emissions towards the trillionth tonne. Nature, 458(7242), 1163-1166.

Bohm, P. (1993). Incomplete international cooperation to reduce CO2 emissions: alternative policies. Journal of Environmental Economics and Management, 24, 258-271.

Chakravorty, U., A. Leach and M. Moreaux (2012). Cycles in non-renewable resource prices with pollution and learning-by-doing. Journal of Economic Dynamics \& Control, 36, 1448-1461.

Chakravorty, U., B. Magne and M. Moreaux (2006). A Hotelling model with a ceiling on the stock of pollution. Journal of Economic Dynamics 86 Control, 30(12), 2875-2904. 
Chakravorty, U., M. Moreaux and M. Tidball (2008). Ordering the Extraction of Polluting Nonrenewable Resources. American Economic Review, 98(3), 1128-44.

Crutzen, P., A. Mosier, K. A. Smith and W. Winiwarter (2008). N2O release from agro-biofuel production negates global warming reduction by replacing fossil fuels. Atmospheric Chemistry and Physics, 8, 389-395.

Fargione, J., J. Hill, D. Tilman, S. Polasky and P. Hawthorne (2008). Land clearing and the biofuel carbon dept. Science, 319, 1235-1238.

Farzin, Y. and O. Tahvonen (1996). Global carbon cycle and the optimal path of a carbon tax. Oxford Economic Papers, New Series, 48, 515-536.

Gerlagh, R. (2011). Too Much Oil. CESifo Economic Studies, 57(1), 79-102.

Grafton, R., T. Kompas and N. Long (2010). Biofuels subsidies and the green paradox. CESifo Working Paper no. 2960.

Hanson, D. A. (1980). Increasing Extraction Costs and Resource Prices: Some Further Results. The Bell Journal of Economics, 11(1), 335-342.

Harstad, B. (2012). Buy Coal! A Case for Supply-Side Environmental Policy. Journal of Political Economy, 120(1), 77-115.

Heal, G. (1976). The Relationship between Price and Extraction Cost for a Resource with a Backstop Technology. The Bell Journal of Economics, $7(2), 371-378$.

Hoel, M. (1994). Efficient climate policy in the presence of free riders. Journal of Environmental Economics and Management, 27 (3), 259-274.

Hoel, M. (2011). The green paradox and greenhouse gas reducing investments. International Review of Environmental and Resource Economics, 5(4), 353-379.

Hoel, M. (2012). Carbon taxes and the green paradox. In R. Hahn, R. and U. Ulph (eds.), Climate Change and Common Sense: Essays in Honour of Tom Schelling. Oxford University Press.

Hoel, M. and S. Kverndokk (1996). Depletion of fossil fuels and the impacts of global warming. Resource and Energy Economics, 18(2), 115-136.

Le Kama, A., M. Fodha and G. Lafforgue (2009). Optimal carbon capture and storage policies. Toulouse School of Economics Working Paper 09-095. 
Long, N. and H.-W. Sinn (1985). Surprise Price Shifts, Tax Changes and the Supply Behavior of Resource Extracting Firms. Australian Economic Papers, 24 (45), 278-289.

Searchinger, T., R. Heimlich, R. Houghton, F. Dong, A. Elobeid, J. Fabiosa, S. Tokgoz, D. Hayes and T.-H. Yu (2008). Use of U.S. Croplands for Biofuels Increases Greenhouse Gases Through Emissions from Land-Use Change. Science, 319, 1238-1241.

Sinclair, P. (1992). High does nothing and rising and worse: carbon taxes should be kept declining to cut harmful emissions. Manchester School of Economic and Social Studies, 60, 41-52.

Sinn, H. (2008a). Das Grüne Paradoxon. Plädoyer für eine Illusionsfreie Klimapolitik. Econ.

Sinn, H. (2008b). Public policies against global warming: a supply side approach. International Tax and Public Finance, 15, 360-394.

Strand, J. (2007). Technology Treaties and Fossil Fuels Extraction. The Energy Journal, 28 (4), 129-142.

Tahvonen, O. (1995). Dynamics of pollution control when damage is sensitive to the rate of pollution accumulation. Environmental and Resource Economics, 5, 9-27.

Ulph, A. and D. Ulph (1994). The optimal time path of a carbon tax. Oxford Economic Papers, 46, 857-868.

van der Ploeg, F. and C. Withagen (2012). Too much coal, too little oil. Journal of Public Economics, 96(1), 62-77.

van der Ploeg, F. and C. A. Withagen (2010). Is There Really a Green Paradox? CESifo Working Paper no. 2963.

Withagen, C. (1994). Pollution and exhaustibility of fossil fuels. Resource and Energy Economics, 16, 235-242. 

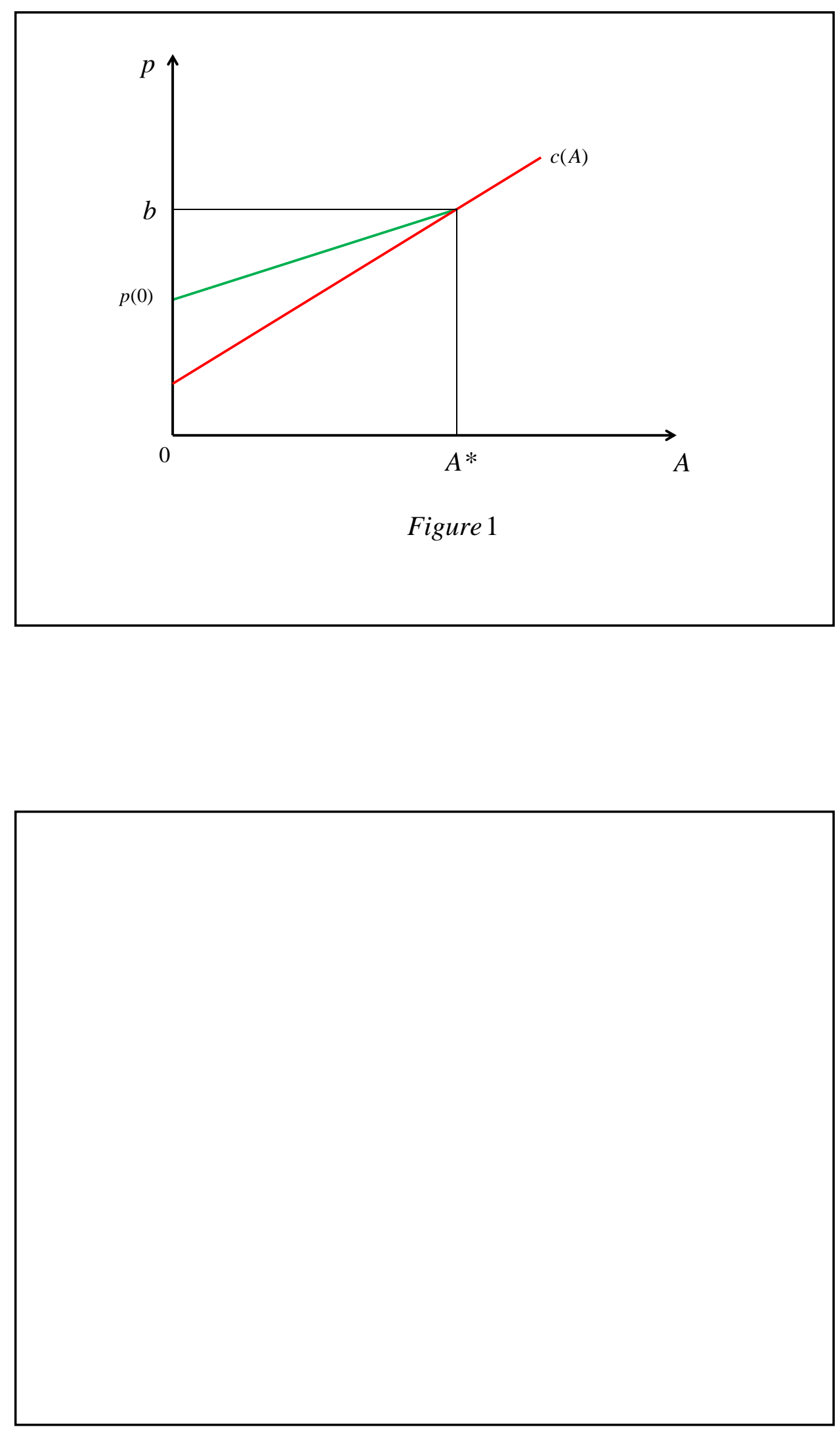

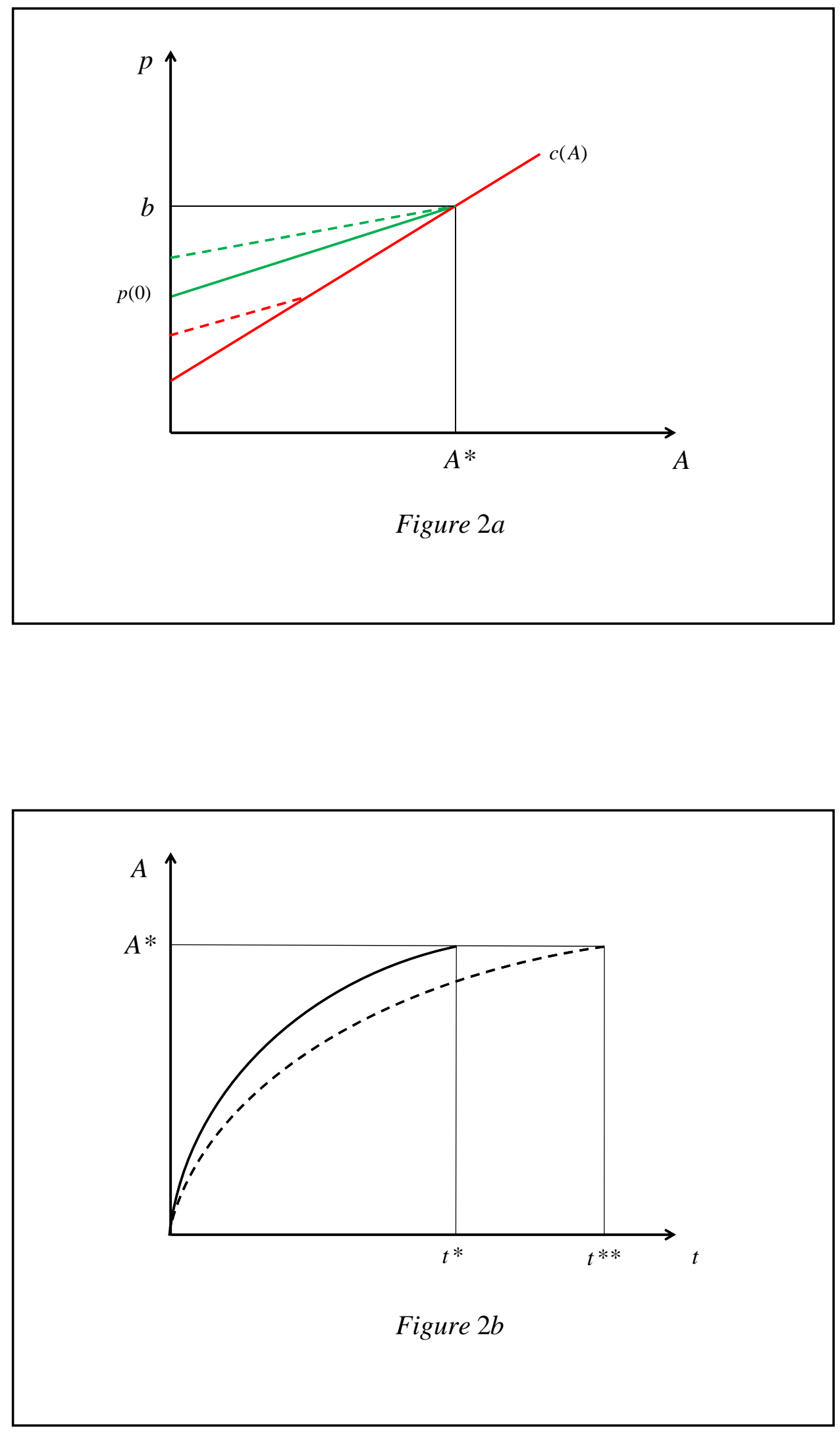

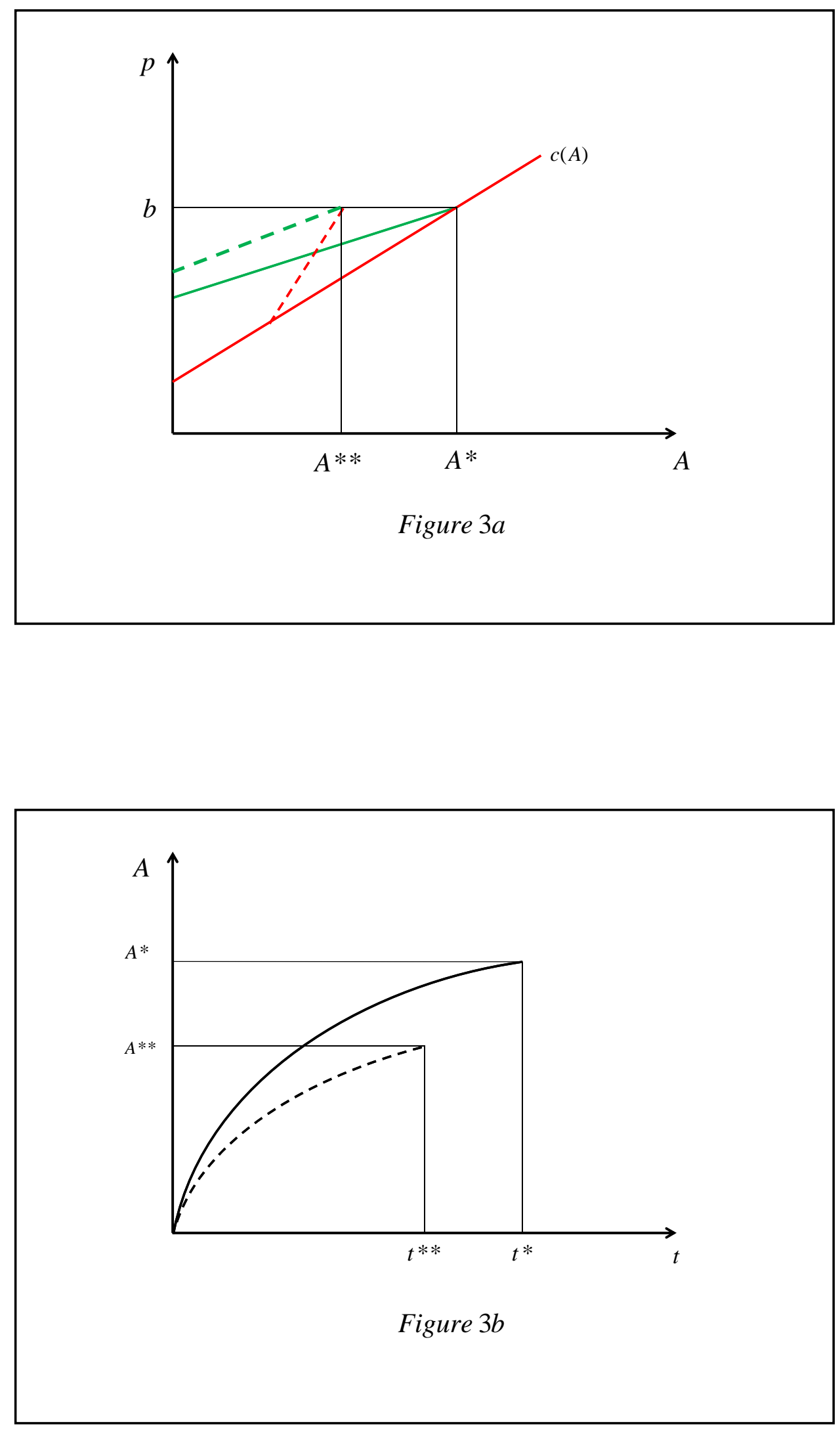

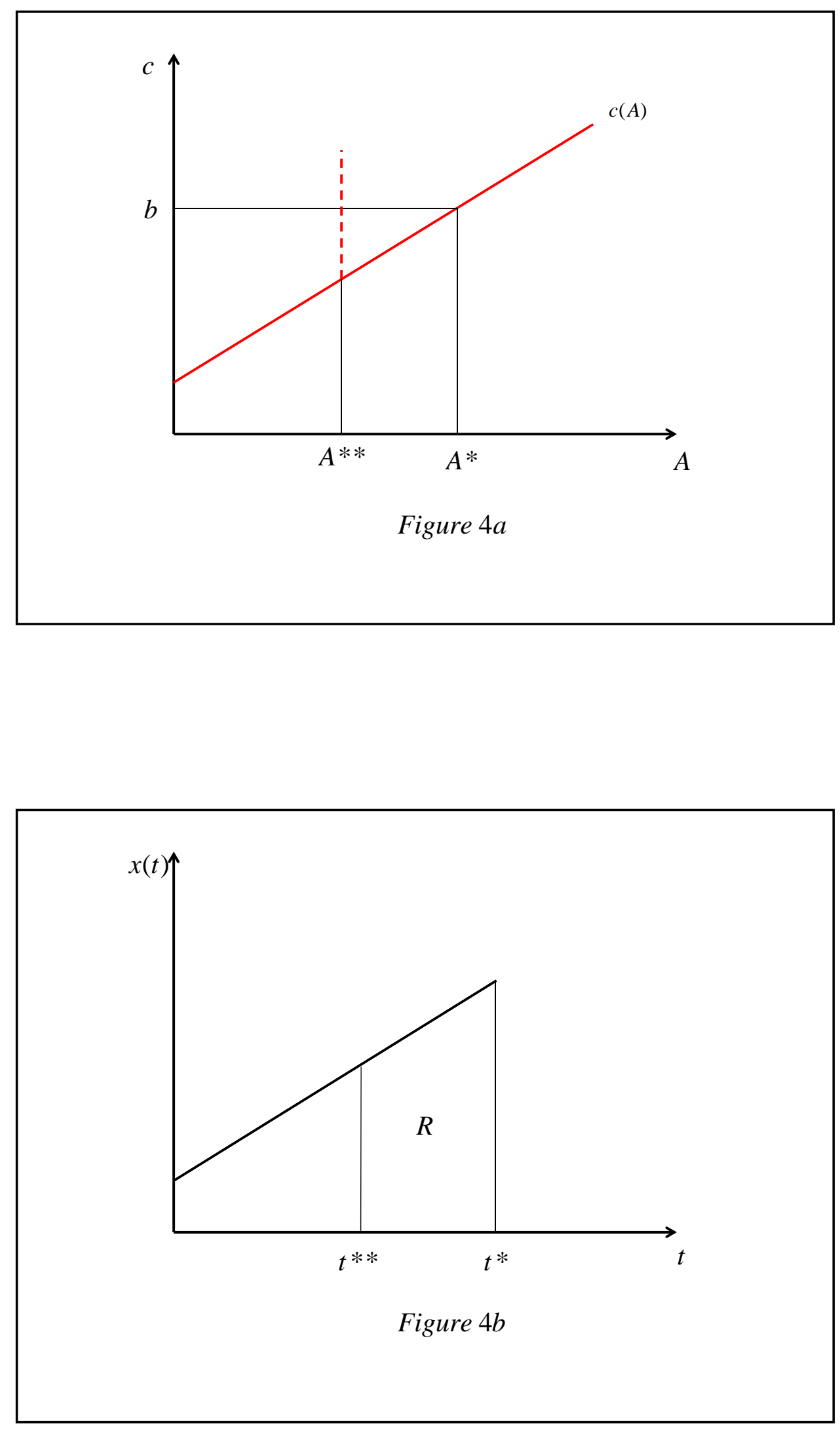


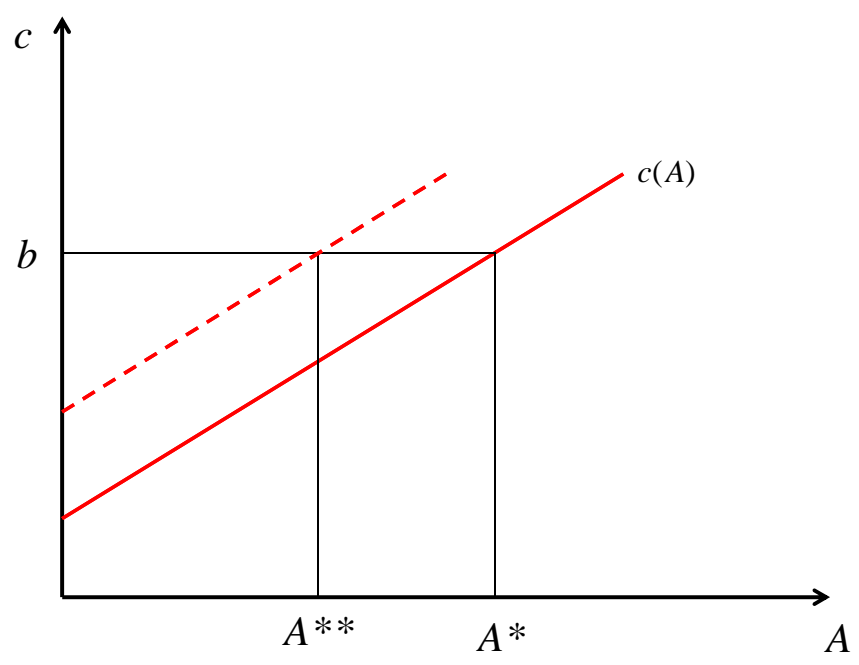

Figure $5 a$

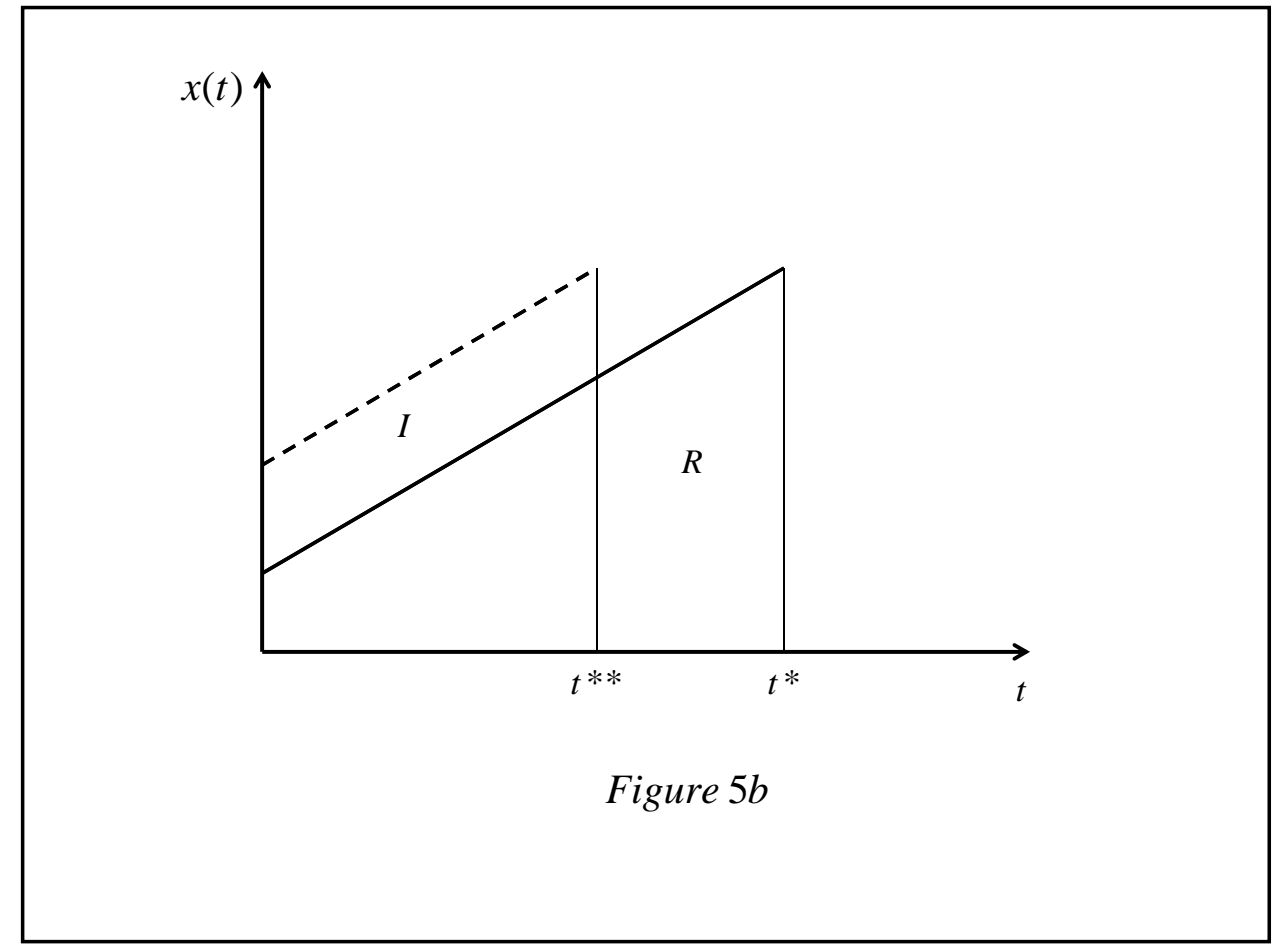



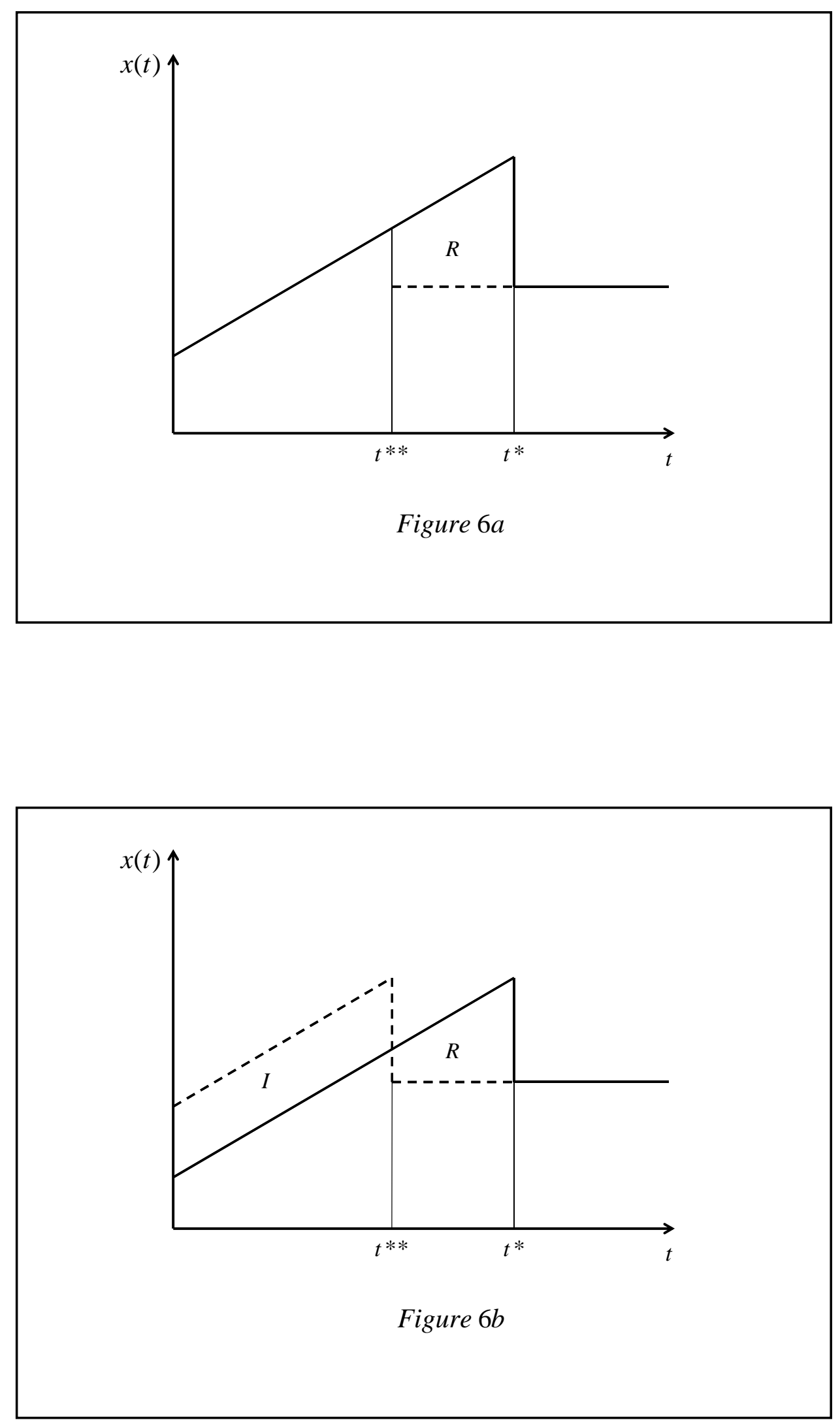